\title{
STUDI PENDAHULUAN SIMULASI NUMERIKAL METODE ELEMEN HINGGA SAMBUNGAN BALOK-KOLOM BAJA TIPE CLIP-ANGLE
}

\author{
Yonathan Aditya Santoso $^{1}$, Noek Sulandari ${ }^{2}$, Yosafat Aji Pranata ${ }^{3}$ \\ Jurusan Teknik Sipil, Fakultas Teknik, Universitas Kristen Maranatha \\ Jalan Prof. drg. Suria Sumantri, MPH., No. 65, Bandung, 40164 \\ E-mail: yonathanaditya90@hotmail.com
}

\begin{abstract}
ABSTRAK
Penggunaan struktur baja yang dapat di terapkan dalam lapangan adalah untuk pembangunan baja, gudang atap suatu gedung atau sekolah, sebagai rangka konstruksi suatu jembatan dan konstruksi pengeboran lepas pantai. Sambungan balok ke kolom dapat di klasifikasikan menjadi sambungan kaku, sambungan geser sederhana, sambungan semi kaku. Metode Elemen Hingga (Finite Element Method) adalah suatu metode numerik dengan tujuan memperoleh pemecahan pendekatan dari suatu persamaan diferensial parsial (Partial Differential Equation). Tujuan dari penelitian ini adalah mempelajari simulasi numerik metode elemen hingga dengan perangkat lunak komputer untuk studi kasus sambungan balok ke kolom, Membandingkan hasil simulasi numerik metode elemen hingga dengan hasil eksperimental dari Hu et.al.. Dari hasil simulasi numerikal dapat diperoleh informasi mengenai slip pada baut, yaitu 0,0411 mm (untuk beban $200000 \mathrm{~N}$ ). Mengingat toleransi lubang baut adalah $2 \mathrm{~mm}$ maka slip ini terjadi masih dalam rentang celah antara lubang baut dengan permukaan baut. Kesimpulannya sambungannya kaku. Pada beban 200000 N ( beban batas Proposional), lendutan pada balok yang terjadi adalah sebesar 1,056 mm (batasan ijin 1,99 mm). Artinya pada rentang beban elastik, lendutan yang terjadi masih memenuhi batasan ijin. Simulasi numerikal dengan perangkat lunak ADINA mempunyai manfaat yaitu, dapat digunakan untuk mengetahui besarnya slip pada sambungan.
\end{abstract}

Kata Kunci: sambungan balok-kolom, clip-angle, metode elemen hingga, elastik.

\begin{abstract}
The Use of steel structure that can be of steel shed roof of a building or a school, a frame construction of a bridge and construction of offshore drilling. Beam to coloum connections can be classified into rigid connections, the connection is simple shear, semi-rigid connections. Finite Element Method is a numerical method in order to obtain an approximation of the solution of partial differensial equations Partial Differential Equation). The purpose of this research to study the finite element method numerical simulations with thw computer sofware, comparing the results of numerical simulations of the finite element method with experimental result from $\mathrm{Hu}$ et.al.. From the numerical simulation results can be obtrained information about the slip on the bolt, which is 0,0411 $\mathrm{mm}$ ( to $200000 \mathrm{~N}$ load). The tolerance of the bolt holes are $2 \mathrm{~mm}$ then the slip is occurring is in the range of the gap between the screw holes with surface of the bolt. At $200000 \mathrm{~N}$ load (proportional limid load), the beam deflections that occurs is 0f 1,056 mm permit under the provisions of the allowable limit is equal to 1,99 $\mathrm{mm}$. This is in the range of elastic load, deflection could still meet the permit limits. Numerical simulation with ADINA software has benefits that can be used to determine the amount of slip on connection.
\end{abstract}

Keywords : beam-coloum connections, clip-angle, finite element method, elastic. 


\section{PENDAHULUAN}

Sambungan balok ke kolom dapat di klasifikasikan menjadi: sambungan kaku, sambungan geser sederhana, sambungan semi kaku. Sambungan kaku adalah sambungan dengan kekakuan yang cukup untuk mempertahankan sudut asli antara bagian berpotongan hampir tidak berubah di bawah beban desain. Sambungan geser sederhana adalah sambungan pengekangan rotasi nol pada sambungannya. Sambungan semi kaku adalah sambungan yang memiliki kapasitas momen diandalkan dan dalam rentang derajat untuk kekakuan sambungan kaku dan fleksibilitas sambungan geser sederhana.

Tujuan penelitian adalah mempelajari simulasi numerik metode elemen hingga dengan perangkat lunak komputer untuk studi kasus sambungan balok ke kolom baja dan membandingkan hasil simulasi numerik metode elemen hingga dengan hasil eksperimental dari Jong-Wan Hu, Roberto T. Leon, and Eunsoo Choi (Hu et.al., 2011).

Ruang lingkup penelitian adalah sebagai berikut:

1. Jenis sambungan yang digunakan adalah baut.

2. Data penelitian eksperimental sambungan baja menggunakan sumber literatur [JongWan Hu, Roberto T. Leon, and Eunsoo Choi, 2011].

3. Perilaku yang dipelajari adalah slip pada baut akibat adanya beban yang bekerja.

4. Perangkat lunak menggunakan ADINA [ADINA, 8.6], dengan pertimbangan dapat memodelkan problem kontak antara baut terhadap lubang, antara pelat penyambung dengan balok-kolom, serta dapat memodelkan Slip.

5. Beban yang ditinjau masih dalam rentang elastik.

\section{TINJAUAN PUSTAKA}

\subsection{Sambungan Baja (Vinnakota, 2006; Salmon dan Johnson, 2009)}

Semua sambungan memberikan beberapa batasan untuk rotasinya agar batangbatang dapat terhubung dengan baik. Berdasarkan hal ini maka sambungan balok-kekolom dapat di klasifikasikan menjadi sambungan kaku, sambungan geser sederhana dan sambungan semi kaku. Sambungan kaku adalah sambungan dengan kekuatan yang cukup untuk mempertahankan sudut asli dengan konstan selama pembebanan. Sambungan geser sederhana terjadi jika kekangan rotasi pada ujung-ujung batang di buat sekecil mungkin atau nol untuk menahan sambungan. Untuk balok, perangkaan sederhana diharapkan hanya memberikan gaya geser pada ujung-ujungnya.

Sambungan semi kaku adalah sambungan yang memiliki kapasitas momen yang dapat di andalkan atau dikenal sebagai gabungan antara kekakuan sambungan kaku dan fleksibilitas sambungan geser sederhana. Proses kekakuan cukup untuk mengembangkan 
tahanan penuh untuk gaya geser dan momen lentur. Sambungan geser sederhana dirancang untuk memberikan gaya geser saja dengan asumsi tidak terjadi momen lentur pada sambungan tersebut. Sambungan semi kaku dirancang untuk menahan gaya geser dan momen lentur yang nilainya adalah diantara nilai untuk sambungan geser sederhana dan kaku penuh.

Dalam sebuah sambungan dudukan-tanpa pengaku, suatu balok ditumpu pada dudukan, dengan atau tanpa pengaku, dirancang untuk menahan seluruh reaksi, akan tetapi harus selalu digunakan bersama dengan siku pengapit atas yang dimaksudkan memberikan tumpuan lateral pada flens tekan. Sambungan dudukan dimaksudkan untuk mentranfer reaksi vertikal saja, dan tidak memberikan momen tahanan yang signifikan pada ujung balok, sehingga dudukan dan siku-siku atas harus relatif fleksibel. Balok akhir bertumpu pada kaki dari sudut, disebut sudut dudukkan, yang lain kaki dalam bergerak atau dilas ke batang pendukung. Sudut dudukan biasanya melekat pada batang pendukung. Ini adalah jenis utama dari sambungan digunakan untuk menghubungkan balok ke badan kolom. Sambungan yang diletakan tidak kaku juga digunakan menghubungkan balok ke sayap kolom.

Sambungan dudukan berpengaku terdiri dari dudukan pelat, elemen kaku dan sudut atas, dudukan kaku dapat dibaut atau dilas. Sambungan dudukan kaku baut terdiri dari dudukan pelat kaku oleh sepasang sudut. Sambungan dudukan kaku las terdiri dari dua pelat. Sambungan dudukan berpengaku tidak dimaksudkan sebagai bagian dari sambungan penahan momen, tetapi lebih sebagai penumpu beban vertikal.

\subsection{Metode Elemen Hingga}

Dalam mekanika struktur sifat material yang mengalami tegangan nonlinier diperhitungkan karena menyebabkan runtuh atau rangkak, dan munculnya tekuk lokal. Material disebut nonlinier apabila sifat dari material adalah fungsi dari kondisi tegangan atau regangan, termasuk elastisitas nonlinier, plastisitas dan rangkak. Masalah yang timbul dalam material adalah material menjadi nonlinier karena kekakuan, dan kemungkinan termasuk akibat beban yang menjadi fungsi dari peralihan atau deformasi (ADINA, 2009).

Penyelesaian perhitungan tegangan nonlinier dapat menggunakan variabel dari aljabar, differensial suatu daerah serta memenuhi syarat-syarat batas. Penentuan syarat batas adalah tidak mudah meskipun untuk masalah sederhana. Metode Elemen Hingga (Finite Element Method) adalah suatu metode numerik dengan tujuan memperoleh 
pemecahan pendekatan dari suatu persamaan diferensial parsial (Partial Differential Equation).

Pada metode elemen hingga kesulitan dalam metode numerik dan penentuan syarat-syarat batas dapat diatasi dengan membagi sebuah kontinum menjadi bagianbagian kecil yang disebut elemen, sehingga solusi dalam tiap bagian kecil dapat dinyatakan dalam fungsi yang jauh lebih sederhana daripada fungsi untuk keseluruhannya. Bagian-bagian kecil tadi secara matematis dihubungkan satu sama lain dengan kondisi sedemikian sehingga kompatibel dan kontinum antar bagian kecil atau elemen.

Perangkat lunak ADINA adalah sebuah perangkat lunak yang dipakai untuk memudahkan pengguna karena dapat melakukan analisis nonlinier dengan pertambahan beban dinamik secara otomatis. Elemen 3-D solid adalah elemen dengan 4-20 titik nodal atau elemen isoparametric dengan 21 atau 27 titik nodal yang dapat diaplikasikan untuk analisis umum elemen 3-D solid. Time step dapat ditentukan oleh pengguna atau dapat dihitung secara otomatis. Ketika pengguna menentukan waktunya maka program ini tidak dapat melakukan apapun untuk memeriksa stabilitas. Hal ini, untuk memastikan bahwa time step yang tepat stabil digunakan, yaitu dengan cara mendefinisikan time step untuk mengontrol waktu atau beban. Setiap baris masukan mendefinisikan sejumlah langkah yang harus di ambil untuk ukuran langkah yang diberikan. Satu blok waktu didefinisikan dengan satu langkah dari ukuran langkah.

Dalam analisis statis dimana efek waktu tidak tergantung terhadap model bahan, maka waktu adalah variable "dummy” yang digunakan, melalui fungsi waktu terkait dari masing-masing beban yang diterapkan, untuk menentukan langkah intensitas beban. Dengan demikian selisih time step langsung menetapkan kenaikan beban.

Metode load-displacement-control (metode panjang busur) dapat digunakan untuk memecahkan persamaan keseimbangan model nonlinier sampai keruntuhannya. Jika diinginkan, pasca respon runtuhnya model ini juga dapat dihitung. Fitur utama dari metode ini adalah bahwa tingkat beban eksternal diatur secara otomatis oleh program ini. Metode LDC hanya dapat digunakan dalam analisis statis nonlinier dimana tidak ada suhu, laju- regangan, tekanan pipa internal. 


\section{STUDI KASUS DAN PEMBAHASAN}

Data model struktur yang digunakan dalam penelitian ini adalah sebagai berikut :

- $\quad$ Kolom : H360x216 (W14x145)

- $\quad$ Balok : H460x60 (W18x40)

- $\quad$ Clip Angle-Connections : L203x153x25.4

- $\quad$ Tipe Baut : ASTM A490 dengan diameter 22 M 10.8

- Data material yang digunakan adalah sebagai berikut:

- $\quad$ Mutu baja : FE 350 (grade steel 50, fy = $350 \mathrm{MPa}$ )

- $\quad$ Modulus Elastisitas : $\mathrm{E}=200000 \mathrm{MPa}$

Langkah awal dalam analisa statik adalah membentuk komponen struktur secara tiga dimensi balok-kolom. Berikut ini langkah-langkah dalam memodelkan komponen diatas dengan menggunakan program ADINA 8.6. Membuat model baru dengan ketentuan sebagai berikut: Kolom H360x216 (W14x145), Balok H460x60 (W18x40), Clip AngleConnections L203x153x25.4, dan tipe baut ASTM A490 dengan diameter 22 M 10.8 (Gambar 1). Pada penelitian ini, dilakukan pemodelan contact problem. Contact yang dilakukan antara baut dengan pelat siku, antara baut dengan flens balok dan flens kolom dan antara pelat siku dengan flens balok dan flens kolom.

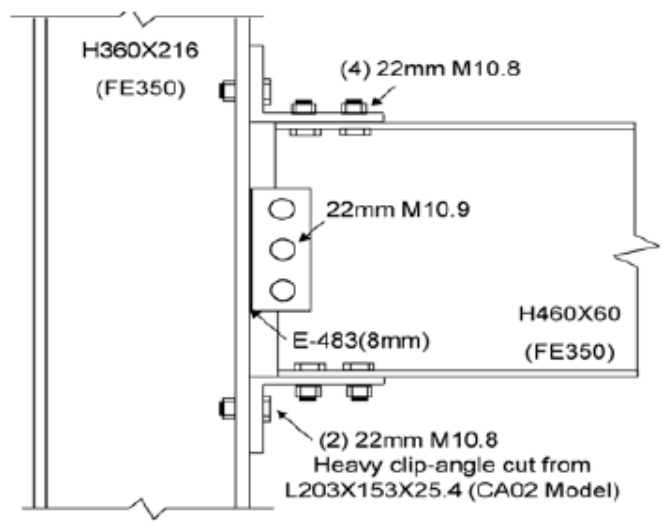

Gambar 1. Sambungan Clip-Angle [Hu et.al., 2011].

Berdasarkan hasil penelitian ini displacement maksimum (Gambar 2) di ujung balok pada beban $100000 \mathrm{~N}$ terletak pada titik nodal 2 dengan nilai 0,5280 mm. Pada beban $200000 \mathrm{~N}$ displacement maksimum di ujung balok terletak pada titik nodal 2 dengan nilai 1,056 $\mathrm{mm}$. Seperti terlihat dalam tampilan berikut yang menunjukan letak elemen yang ditinjau. 


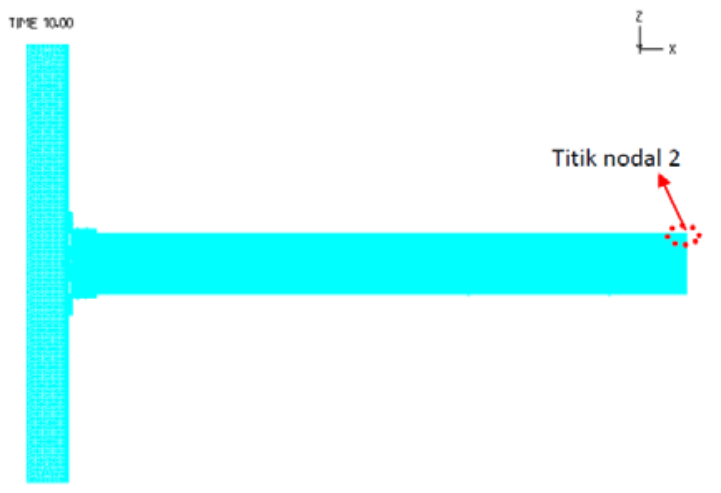

\section{Gambar 2. Tampilan titik nodal dan elemen yang ditinjau.}

Gambar 3 memperlihatkan kurva hubungan antara beban vs lendutan berdasarkan hasil analisis metode elemen hingga. Pada beban $100000 \mathrm{~N}$ dan beban $200000 \mathrm{~N}$ menunjukan fase elastis, dimana pada fase ini hubungan tegangan regangan adalah linier.

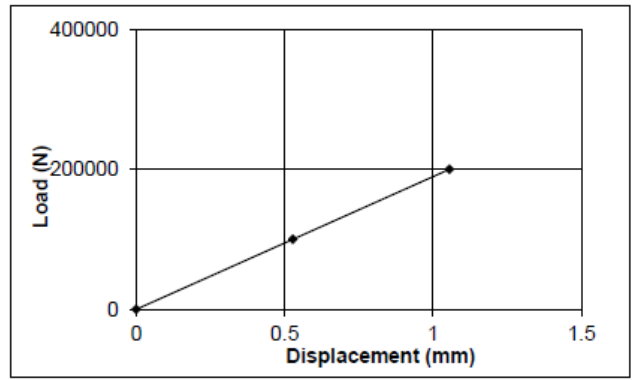

Gambar 3. Kurva hubungan beban vs lendutan tinjauan pada titik nodal 2.

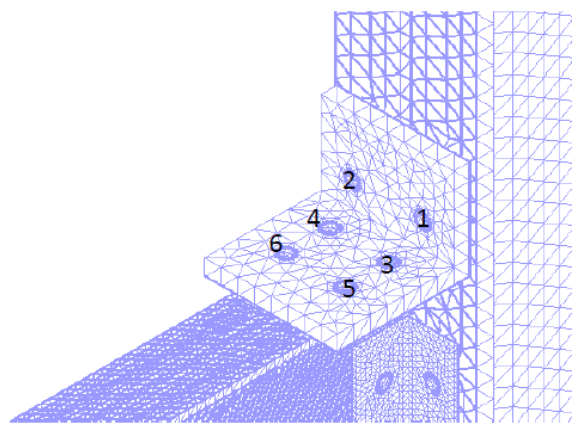

(a). Bagian atas.

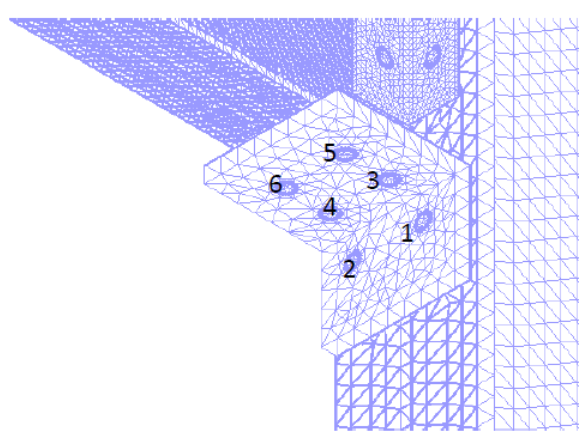

(b). Bagian bawah.

Gambar 4. Tampilkan clip-angle.

Hasil bacaan displacement (selanjutnya disebut slip pada baut) untuk baut yang dipasang pada clip-angle bagian atas selengkapnya ditampilkan pada Tabel 1 dan Tabel 2 (Gambar 4). Sedangkan untuk clip-angle bagian bawah selengkapnya ditampilkan pada 
Tabel 3 dan Tabel 4. Kemudian hasil bacaan slip baut pada pelat yang dipasang pada masing-masing sisi depan dan belakang (web) balok untuk menyambung dengan kolom selengkapnya ditampilkan pada Tabel 5, Tabel 6, Tabel 7, dan Tabel 8.

Tabel 1. Slip pada baut clip-angle bagian atas akibat beban $100000 \mathrm{~N}$.

\begin{tabular}{|c|c|c|c|}
\hline \multirow{2}{*}{ \# Baut } & \multicolumn{3}{|c|}{ Translasi (mm) } \\
\cline { 2 - 4 } & $\mathbf{X}$ & $\mathbf{Y}$ & $\mathbf{Z}$ \\
\hline 1 & 0 & 0,0032 & 0 \\
\hline 2 & 0 & 0,0022 & 0 \\
\hline 3 & 0,0363 & 0,0356 & 0,1302 \\
\hline 4 & 0,0370 & 0,0363 & 0,1329 \\
\hline 5 & 0,0029 & 0,0029 & 0,0098 \\
\hline 6 & 0,0034 & 0,0035 & 0,0125 \\
\hline
\end{tabular}

Tabel 2. Slip pada baut clip-angle bagian bawah akibat beban $200000 \mathrm{~N}$.

\begin{tabular}{|c|c|c|c|}
\hline \multirow{2}{*}{ \# Baut } & \multicolumn{3}{|c|}{ Translasi (mm) } \\
\cline { 2 - 4 } & $\mathbf{X}$ & $\mathbf{Y}$ & $\mathbf{Z}$ \\
\hline 1 & 0 & 0,0029 & 0 \\
\hline 2 & 0 & 0,0295 & 0 \\
\hline 3 & 0,0737 & 0,0728 & 0,2640 \\
\hline 4 & 0,0747 & 0,0738 & 0,2676 \\
\hline 5 & 0,0076 & 0,0076 & 0,0257 \\
\hline 6 & 0,0082 & 0,0082 & 0,0294 \\
\hline
\end{tabular}

Tabel 3. Slip pada baut clip-angle bagian atas akibat beban $100000 \mathrm{~N}$.

\begin{tabular}{|c|c|c|c|}
\hline \multirow{2}{*}{ \# Baut } & \multicolumn{3}{|c|}{ Translasi (mm) } \\
\cline { 2 - 4 } & $\mathbf{X}$ & $\mathbf{Y}$ & $\mathbf{Z}$ \\
\hline 1 & 0,0003 & 0,0030 & 0,0008 \\
\hline 2 & 0,0003 & 0,0030 & 0,0008 \\
\hline 3 & 0,0751 & 0,0743 & 0,1876 \\
\hline 4 & 0 & 0,0022 & 0 \\
\hline 5 & 0,0735 & 0,0760 & 0,1832 \\
\hline 6 & 0,0993 & 0,00225 & 0,1973 \\
\hline
\end{tabular}

Tabel 4. Slip pada baut clip-angle bagian bawah akibat beban $200000 \mathrm{~N}$.

\begin{tabular}{|c|c|c|c|}
\hline \multirow{2}{*}{ \# Baut } & \multicolumn{3}{|c|}{ Translasi (mm) } \\
\cline { 2 - 4 } & $\mathbf{X}$ & $\mathbf{Y}$ & $\mathbf{Z}$ \\
\hline 1 & 0,0003 & 0,0039 & 0,0011 \\
\hline 2 & 0,0003 & 0,0039 & 0,0011 \\
\hline 3 & 0,1506 & 0,1497 & 0,3770 \\
\hline 4 & 0,2159 & 0,0002 & 0,4658 \\
\hline 5 & 0,1486 & 0,1516 & 0,3270 \\
\hline 6 & 0,2049 & 0,0029 & 0,3896 \\
\hline
\end{tabular}


Tabel 5. Slip pada baut clip-angle bagian depan akibat beban 100000 N.

\begin{tabular}{|c|c|c|c|}
\hline \multirow{2}{*}{ \# Baut } & \multicolumn{3}{|c|}{ Translasi (mm) } \\
\cline { 2 - 4 } & $\mathbf{X}$ & $\mathbf{Y}$ & $\mathbf{Z}$ \\
\hline 1 & 0,0001 & 0,0004 & 0,0001 \\
\hline 2 & 0,0001 & 0,0003 & 0,0001 \\
\hline 3 & 0 & 0,0001 & 0 \\
\hline 4 & 0 & 0,0005 & 0 \\
\hline 5 & 0 & 0,0005 & 0 \\
\hline 6 & 0,0002 & 0,0004 & 0,0001 \\
\hline
\end{tabular}

Tabel 6. Slip pada baut clip-angle bagian depan akibat beban 200000 N.

\begin{tabular}{|c|c|c|c|}
\hline \multirow{2}{*}{ \# Baut } & \multicolumn{3}{|c|}{ Translasi (mm) } \\
\cline { 2 - 4 } & $\mathbf{X}$ & $\mathbf{Y}$ & $\mathbf{Z}$ \\
\hline 1 & 0,0003 & 0,0010 & 0,0003 \\
\hline 2 & 0,0003 & 0,0011 & 0,0004 \\
\hline 3 & 0,0004 & 0,0011 & 0,0004 \\
\hline 4 & 0 & 0,0001 & 0 \\
\hline 5 & 0 & 0,0001 & 0 \\
\hline 6 & 0,0003 & 0,0009 & 0,0002 \\
\hline
\end{tabular}

Tabel 7. Slip pada baut clip-angle bagian belakang akibat beban $100000 \mathrm{~N}$.

\begin{tabular}{|c|c|c|c|}
\hline \multirow{2}{*}{ \# Baut } & \multicolumn{3}{|c|}{ Translasi (mm) } \\
\cline { 2 - 4 } & $\mathbf{X}$ & $\mathbf{Y}$ & $\mathbf{Z}$ \\
\hline 1 & 0,0007 & 0,0017 & 0 \\
\hline 2 & 0,0007 & 0,0008 & 0 \\
\hline 3 & 0,0004 & 0,0005 & 0 \\
\hline 4 & 0 & 0,0005 & 0 \\
\hline 5 & 0 & 0,0005 & 0 \\
\hline 6 & 0 & 0,0005 & 0 \\
\hline
\end{tabular}

Tabel 8. Slip pada baut clip-angle bagian belakang akibat beban $200000 \mathrm{~N}$.

\begin{tabular}{|c|c|c|c|}
\hline \multirow{2}{*}{ \# Baut } & \multicolumn{3}{|c|}{ Translasi (mm) } \\
\cline { 2 - 4 } & $\mathbf{X}$ & $\mathbf{Y}$ & $\mathbf{Z}$ \\
\hline 1 & 0,0012 & 0,0028 & 0 \\
\hline 2 & 0,0010 & 0,0012 & 0 \\
\hline 3 & 0,0007 & 0,0009 & 0 \\
\hline 4 & 0 & 0,0010 & 0 \\
\hline 5 & 0 & 0,0010 & 0 \\
\hline 6 & 0 & 0,0010 & 0 \\
\hline
\end{tabular}

Berikut ini adalah tabel perbandingan hasil simulasi dengan hasil eksperimental untuk slip baut. Perhitungan slip baut diasumsikan sebagai nilai ratarata dari nilai slip seluruh baut (yaitu translasi-x) pada tinjauan sambungan pelat atas terhadap flens balok. 
Tabel 9. Perbandingan hasil simulasi numerikal terhadap tinjauan literatur (hasil eksperimental) untuk beban $100000 \mathrm{~N}$.

\begin{tabular}{|c|c|c|}
\hline Slip baut & ADINA & Eksperimental \\
\hline Arah-x & 0,0199 & $<0,1 \mathrm{~mm}$ \\
\hline Arah-y & 0,0196 & - \\
\hline Arah-z & 0,0714 & - \\
\hline
\end{tabular}

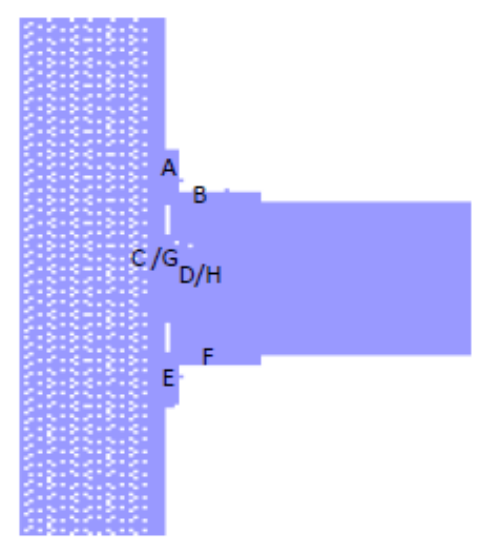

Gambar 5. Skematik tampak samping model sambungan balok-kolom.

Secara umum, slip yang terjadi pada baut, untuk masing-masing pelat sisi atas dan bawah yang menyambung pada flens balok terhadap kolom, dan masing-masing pelat sisi kiri dan kanan yang menyambung pada web balok terhadap kolom, hasilnya yaitu slip bagian B (tranlasi-x) = 0,0199 mm dan slip bagian F (tranlasi-x) = 0,06197 mm (Gambar $5)$.

\section{KESIMPULAN DAN SARAN}

Kesimpulan yang dapat diambil dari hasil penelitian ini adalah sebagai berikut:

1. Dari hasil simulasi numerikal dapat diperoleh informasi mengenai slip pada baut, yaitu 0,0411 mm (untuk beban $200000 \mathrm{~N}$ ). Mengingat toleransi lubang baut adalah 2 mm maka slip ini terjadi masih dalam rentang celah antara lubang baut dengan permukaan baut.

2. Pada beban 200000 N (beban batas Proposional), lendutan pada balok yang terjadi adalah sebesar 1,056 mm. Berdasarkan ketentuan ijin batasan yang diijinkan adalah sebesar 1,99 mm. Artinya pada rentang beban elastik, lendutan yang terjadi masih memenuhi batasan ijin.

3. Simulasi numerikal dengan perangkat lunak ADINA mempunyai manfaat yaitu, dapat digunakan untuk mengetahui besarnya slip pada baut. 
Mengingat keterbatasan lingkup penelitian yang telah dilakukan dalam penelitian ini, maka saran yang disampaikan adalah sebagai berikut ini:

1. Perlunya dilakukan penelitian lebih lanjut untuk mempelajari perilaku sambungan balok-kolom pada rentang beban pasca elastik.

2. Perlunya mempelajari pengaruh besarnya pretension pada baut dan tegangan yang terjadi pada baut.

\section{DAFTAR PUSTAKA}

1. Adina Solids \& Structures Definition , Inc, May, 2009, “ADINA version 8.6.”, Adina R \& D, Inc., Watertown, MA 02472 USA.

2. Badan Standardisasi Nasional, 2002, Standar Perencanaan struktur baja untuk Bangunan Gedung (SN1 03-1729-2002).

3. Jong-Wan Hu1, Roberto T. Leon2, and Eunsoo Choi3, March, 2011, International Journal of Steel Structures, Vol 11, No 1, 1-1.

4. Setiawan, A., 2008, Perencanaan Struktur Baja dengan Metode LRFD, Erlangga.

5. Vinnakota, S., 2006, Steel Structure : Behavior and LRFD, McGraw-hill Companies, Singapore.

6. Charles G. Salmon, John E. Johnson. 2009, Steel Structures Design and Behavior Fifth Edision, Pearson Prentice Hall, New Jersey.

7. James M. Gere, Stephen P. Timoshenko. 1996 , Mekanika Bahan Jilid 2 Edisi Keempat, Erlangga, Jakarta. 